\title{
The impact of US macroeconomic news on the Polish stock market
}

\section{The importance of company size to information flow}

\author{
Henryk Gurgul · Tomasz Wójtowicz
}

(C) The Author(s) 2014. This article is published with open access at Springerlink.com

\begin{abstract}
This paper investigates the impact of US macroeconomic news announcements on the intraday returns of Warsaw Stock Exchange indices. The WSE is the largest and the most liquid stock market among the new European Union member countries. By means of an event study we examine the response of three indices, namely the WIG20, the mWIG40 and the sWGI80, describing the stock price behavior of the largest, medium-sized and small firms, respectively. The results of the empirical analysis show that the stock prices of the largest firms react in the first minute after a news release. This indicates the relatively high efficiency of the WSE. The response of smaller firms' stock returns is slower but more persistent. The most influential are the announcements of Nonfarm Payrolls describing the US labor market. The indices of the WSE react similarly to good and bad news about the US economy.
\end{abstract}

Keywords Event study · Macroeconomic announcements · Intraday data

JEL Classification G14 $\cdot$ E44

Financial support for this paper from the National Science Centre of Poland (Research Grant DEC-2012/05/B/HS4/00810) is gratefully acknowledged.

H. Gurgul $(\varangle) \cdot$ T. Wójtowicz

Department of Applications of Mathematics in Economics, Faculty of Management, AGH University of Science and Technology, Al. Mickiewicza 30, 30-059 Kraków, Poland e-mail: henryk.gurgul@gmail.com

T. Wójtowicz

e-mail: twojtow@agh.edu.pl 


\section{Introduction}

Globalization means that market participants must take into account not only domestic information but also information from markets around the world. Hence, it is intuitively clear that the economic situation in individual countries strongly affects the behavior of international investors. Macroeconomic data are a very important source of information not only about the actual state of real economies but more importantly about their future prospects. This implies that macroeconomic news announcements impact investors' expectations and are the sources of price changes on stock markets. Although Chen et al. (1986) argued that the endogeneity of macroeconomic policy implies that the explanatory power of macroeconomic variables for stock returns is low, there have been a growing number of contributions demonstrating the strong influence of macroeconomic data on stock markets. The majority of these studies concern the impact of US macroeconomic data on the US and to a lesser extent on other developed markets (e.g. Schwert 1981; Pearce and Roley 1985; Li and Hu 1998; Nikkinen and Sahlström 2004; Boyd et al. 2005; Andersen et al. 2007; Harju and Hussain 2011). This is a natural consequence of the US economy being the largest and most important economy in the world.

A similar reaction to US data also can be expected on emerging markets due to their stronger and stronger relationships with developed markets. This process of strengthening mutual relationships is particularly visible in economies from Central and Eastern Europe which are in transition. Their accession to the EU has meant that this part of Europe is subject to a growing influence of highly developed western economies, including the US. This is should be reflected in the sensitivity of stock markets to macroeconomic news from developed countries. However, the impact of macroeconomic announcements from highly developed economies on emerging equity markets in Central and Eastern Europe has been the subject of few contributions (e.g. Nikkinen et al. 2006; Gurgul et al. 2012).

The aim of this paper is to analyze the impact of unexpected news about six US macroeconomic indicators on the behavior of different groups of stocks on the Warsaw Stock Exchange (WSE). The focus on the reaction of the WSE is because it is the largest and most liquid stock market in the region ${ }^{1}$ and because if US data announcements influence the stock markets of new EU members, this impact should be particularly visible on the WSE. Due to the relatively high liquidity of assets the reaction of stock prices on the WSE is expected to be comparable to the reactions of developed markets. Additionally, foreign investors, mainly from the UK and France, own about $49 \%$ of the stocks on the WSE while the share of Polish institutional investors amounts to $37 \%$ and that of individual investors to about $14 \%$. The large proportion of foreign and institutional investors on the WSE suggests a rather high level of efficiency. New public information should be very quickly incorporated into prices and the effect of announcements should be visible just after a news release. Recently it has been proven that US macroeconomic news has an effect on investor behavior and on the stock prices

\footnotetext{
1 According to monthly report of the Federation of European Securities Exchanges (FESE) the total capitalization of the WSE was $126680.7 \mathrm{mln} €$ at the end of April 2013. In this part of Europe only the stock exchanges in Istanbul and Moscow have a larger capitalization than the WSE.
} 
of companies from western countries (e.g. Harju and Hussain 2011). A similar reaction of foreign investors can be expected on the WSE.

In this paper we study the impact of the following US macroeconomic indicator announcements: the Consumer Price Index (CPI), Industrial Production (IP), the Producer Price Index (PPI), Durable Goods Orders (DGO), Retail Sales (RS) and Nonfarm Payrolls (NFP). The behavior of different groups of stocks on the WSE is described by 1-min returns of three WSE indices, namely: WIG20, mWIG40 and sWIG80 which describe stock prices of the largest, medium-sized and small companies, respectively. We also examine the reaction of the WIG index as regards the behavior of almost all stocks on the WSE.

The structure of this paper is as follows. Section 2 presents an overview of the literature related to the impact of macroeconomic announcements on security prices. In Sect. 3, conjectures are formulated and justified. Section 4 describes the data and methodology applied in this study. The empirical results are presented and discussed in Sect. 5. The last section concludes the paper.

\section{Literature review}

Statistical offices in different countries, including federal agencies and bureaus from the US make regularly scheduled public announcements of macroeconomic data about employment, inflation, prices, production, consumption, etc. The effects of these announcements on stock prices, volatility and trading volume have received considerable attention not only in the popular press but also in the academic literature. Krueger (1996) stresses that since 1983 every time the Bureau of Labor Statistics has released employment data, on that day and on the following day, the New York Times quoted the release as influencing the bond or stock market.

In much of the more recent literature there is a wide coverage of the impact of macroeconomic news surprises on financial assets. The contributions by Fleming and Remolona (1997), Bollerslev et al. (2000), Furfine (2001), Balduzzi et al. (2001), and Green (2004) provide evidence that news surprises about macroeconomic data, including GDP, the inflation rate, the unemployment rate and consumer confidence are responsible for changes in Treasury yields especially around the time of the announcements. The intuition concerning the importance of macroeconomic announcements for stock markets is also confirmed by numerous papers. Early studies focused on the US market. Subsequent analyses were extended to other developed markets.

Geske and Roll (1983) posit a negative relation between changes in inflation and stock returns. This relation is observed because expected changes in inflation signal a higher future rate of monetary expansion and thus impact on investors' expectations. Inflation rate announcements affect the financial market not just by changes in expectations about future inflation. Such announcements also have an effect on the real economy by forcing particular actions. For example, unanticipated high inflation could force agents to increase their savings and might be a reason for expecting a more restrictive monetary policy. The consequences of such a reaction would be higher interest rates and lower stock prices. Unexpected new information contained 
in CPI or PPI announcements therefore are likely to be positively related to interest rates and negatively related to stock prices.

These relationships are also confirmed by McQueen and Roley (1993) who examine the impact of various pieces of macroeconomic news on daily data of the S\&P500 from September 1977 to May 1988. They consider e.g. industrial production, the unemployment rate, nonfarm payrolls, CPI and PPI. The results indicate the strong impact of macroeconomic news on stock prices, especially when different stages of the business cycle are taken into account.

Li and Hu (1998) extend previous findings by analyzing the impact of broad sets of macroeconomic announcements (e.g. CPI, PPI, Industrial Production, Unemployment) on daily returns of the DJIA and on the S\&P500 in the period 1980-1996. They find that the reaction of stock prices strongly depends on the state of the economy. From this paper it also follows that the reactions of the stocks of small and large companies are different.

The relations between the stage of an economy and investors' reactions to macroeconomic news announcements is carefully analyzed by Boyd et al. (2005) who study the impact of US Unemployment Rate announcements on the S\&P500 stock index in the period from February 1948 to December 2000. They show that the reaction of the stock market depends on the state of the economy, i.e. during contractions average stock returns are positive when good news is announced and negative on a day of bad news. On the other hand, during expansions the situation is quite different-average stock returns are positive regardless of the information contained in the announcement. The contributors suggest that unemployment news contain information about future interest rates and about future corporate earnings and dividends. An increase in unemployment typically signals a decline in interest rates. This is good news for stocks. However, unemployment is also a reason for a decline in future corporate earnings and dividends, which is bad news for investors. The relative importance of these two effects changes over time and depends on the state of the economy i.e. during expansions information about interest rates dominates, while during contractions it is information about equity risk premiums and future corporate dividends which dominates.

Apart from the impact of macroeconomic announcements on stock prices, evidence on the effect of macroeconomic news on return volatility have been also found. Li and Engle (1998) analyze the effects of scheduled and unscheduled US macroeconomic news on volatility. They find that the impact of unscheduled macroeconomic news on conditional volatility is more persistent. On the other hand, volatility reacts asymmetrically to scheduled announcements; it decreases after positive shocks and increases after negative shocks. Flannery and Protopapadakis (2002) study the impact of the announcements of 17 different macroeconomic data on the daily return volatility of the value-weighted NYSE-AMEX-NASDAQ market index between January 1980 and December 1996. They confirm the significant response of return volatility to CPI, PPI, Monetary Aggregate, Balance Trade, Employment Report and Housing Starts announcements. Also Bonfim (2003) confirms the effect of macroeconomic news (about monetary policy) on the volatility of stock returns.

The impact of US macroeconomic data on other developed countries also has been examined. For example, Nikkinen and Sahlström (2004) use daily data from January 
1996 to December 1999 to study the impact of macroeconomic announcements on the German and Finnish equity markets. Their data set consists of monthly announcements of CPI, PPI and Unemployment Rate from Germany, Finland and the US. The results of the study indicate that domestic macroeconomic data announcements do not influence either the German or the Finnish markets. However, the implied volatility on both markets reacts significantly to US data about the UR and PPI while CPI news impacts only on the Finnish market.

Nikkinen et al. (2006) extend the above study to an analysis of the impact of US macroeconomic indicator announcements on stock markets in the various parts of the world. They consider six groups of countries including some developed markets and emerging markets in Europe, Asia and Latin America. The results indicate differences in the reaction to US macroeconomic data announcements among those regions. Developed countries in Europe and Asia are very sensitive to US data releases with CPI, employment costs and employment situation being the most influential indicators. On the other hand, the reaction of the group of European countries in transition (the Czech Republic, Hungary, Poland, Slovakia and Russia) is insignificant. This leads to the conclusion that there is weak integration between the developed and emerging markets in Europe.

Recently intraday data have been frequently applied in the analysis of stock market reactions to US macroeconomic announcements. On the basis of 5-min returns Andersen et al. (2007) investigate the impact of 22 US macroeconomic indicators on the stock, bond and exchange markets in the US, UK and Germany from July 1998 to end of December 2002. The results of the paper confirm the significant impact of US macroeconomic announcements on the conditional means of European stock markets. The authors also show that stock market reactions depend on the state of the US economy i.e. traditionally bad information has a positive impact on European markets during expansions.

The impact of US macroeconomic releases on European stock markets is also examined by Harju and Hussain (2011). They study a wide set of US macroeconomic news announcements from September 2000 to March 2006. Their findings show that US macroeconomic surprises imply the immediate and significant reaction of intraday volatility and 5-min returns of major European stock indices (i.e. CAC40, DAX30, FTSE100 and SMI).

More detailed data are used by Entorf and Steiner (2007) who study the response of 15-s returns of the German stock market index DAX to announcements of macroeconomic business cycle forecasts. The paper shows that both returns and volatility react significantly and immediately after an announcement, revealing the high level of efficiency of the German stock market. However, the reaction of returns quickly disappears, whereas return volatility remains increased up to 2 min after a news release. The authors also show that unanticipated shocks imply an asymmetric reaction of returns: good news lead to more pronounced reactions than bad news. Moreover, there is evidence of mean reversion and calm-before-the-storm effects.

There is a very limited number of papers concerning the impact of macroeconomic news on emerging markets in Europe. One of them is the paper of Nikkinen et al. (2006) mentioned above. The reaction of 12 emerging bond markets (including Poland) to various US macroeconomic announcements is studied by Andritzky et al. (2007). On 
the basis of country subindices of the Emerging Market Bond Index from January 1998 to July 2004 the authors show that international news is more significant than domestic news. In general, US macroeconomic announcements impact on (reduce) bond spread volatility.

The impact of US macroeconomic data on the Polish stock market is analyzed by Gurgul et al. (2012). They study the reaction of the daily returns of the WIG20 (the main index of the Warsaw Stock Exchange) to announcements about CPI, the Unemployment Rate and Industrial Production in the US. This paper shows that investors significantly respond to CPI and IP unexpected news while UR releases seem to have no impact on the Warsaw Stock Exchange.

\section{Main conjectures}

Taking into account the literature overview we formulate some conjectures about the relationship between the information content of the announcements of six US macroeconomic indicators and the returns of WSE indices.

From event study theory it is well known that good news causes positive abnormal returns and bad news implies negative returns at the event time and after. Hence we expect that the following hypothesis holds true:

Conjecture 1 CPI and PPI announcements below forecast and IP, DGO, RS and NFP above forecast are good news and the intraday returns of WSE indices react positively to them, i.e. these announcements are followed by positive abnormal returns. On the other hand, CPI and PPI announcements above forecast and IP, DGO, RS and NFP below forecast are bad news and imply a negative reaction of the indices, i.e. these announcements are followed by negative abnormal returns of WSE indices.

In light of this hypothesis, we divide all events into two clusters: good news and bad news. In the next step we also analyze the effects of good and bad news irrespective of the announced macroeconomic indicator.

The results from developed markets mentioned in the previous sections prove the instantaneous reaction of stock prices to various macroeconomic data announcements. We conjecture a similar reaction of WSE indices:

Conjecture 2 There is a significant reaction of WSE indices to US macroeconomic indicator announcements immediately after a news release.

In the financial literature the speed of adjustment hypothesis is well known (Brennan et al. 1993). According to it the stocks of firms that are tracked by many analysts tend to react faster than the stocks of firms that are tracked by fewer analysts. In general, the largest companies (i.e. blue chips) listed in the main index of the stock market are the most visible. Their stocks are also the most liquid and trading in such stocks is more transparent and efficient than in the stocks of companies that attract less investor attention. According to the speed of adjustment hypothesis, smaller firms (e.g. those listed in the mWIG40 and sWIG80), attracting less investor attention, react more slowly to public information than large companies listed in the WIG20. Note that we do not distinguish between companies listed in the mWIG40 and the sWIG80, i.e. 
they are in the same cluster because investors pay attention mainly to stocks listed in the WIG20. The other stocks are less visible. Hence we conjecture:

Conjecture 3 The response to US macroeconomic data announcements depends on the size of companies, i.e. the returns of the WIG20 react faster to unexpected news about US macroeconomic indicators than the returns of the mWIG40 and sWIG80. Moreover, the impact of new information on the WIG20 is significant over a shorter period of time after the event than the impact on mWIG40 and sWIG80.

An important topic in the financial literature is the widely observed asymmetrical reaction of stock prices to good and bad news. In general, stock prices overreact to bad news and underreact to good news, i.e. changes in stock prices caused by bad news are larger in their magnitude than changes implied by good news (e.g. Kothari et al. 2009).

Thus, we aim to check the hypothesis:

Conjecture 4 The reaction of WSE indices to bad news is stronger than the reaction to good news.

\section{Data and methodology}

\subsection{Announcements}

In this paper we investigate the impact of the announcements of six US macroeconomic indicators, i.e. the Consumer Price Index (CPI), the Producer Price Index (PPI), Industrial Production (IP), Retail Sales (RS), Durable Goods Orders (DGO) and Nonfarm Payrolls (NFP). We choose these macroeconomic indicators for three reasons. First, they are among the most important US indicators and their impact is widely studied in the literature. ${ }^{2}$ Secondly, announcements about these indicators are released on a monthly basis and they describe the US economy in the previous month. This ensures a sufficient number of important announcements to conduct the study. Thirdly, these indicators are released during trading hours on the WSE and thus their impact can be empirically verified.

Most of the announcements under study are released at 8.30 EST $(14.30 \mathrm{CET}){ }^{3}$ Only Industrial Production is released at 9.15 EST (15.15 CET). Because Daylight Saving Time is introduced in the US one week earlier than in Europe, in some cases the announcements reach the WSE $1 \mathrm{~h}$ earlier i.e. at 13.30 CET and 14.15 CET, respectively. Nevertheless, all announcements under study are released far enough from the period of increased volatility at the beginning and at the end of the trading sessions on the WSE.

In this paper we study the impact of unexpected news contained in US macroeconomic announcements. Thus, for each macroeconomic news release the actual value

\footnotetext{
2 In the majority of papers the unemployment situation in the US is described by the Unemployment Rate. However, as Andersen et al. (2007) show, Nonfarm Payrolls is one of the most significant macroeconomic announcements.

3 EST_Eastern Standard Time, CET_Central European Time.
} 
of the announced indicator is compared with its consensus forecast. All comparisons are performed on the basis of the consensus published by Bloomberg a few days before announcements. It allows us to divide all releases into three clusters: 'above consensus', 'below consensus' and 'in line with consensus'. Because the news in the last cluster is in line with previous investor expectations, our analysis focuses only the first two clusters, which contain unexpected news. In the case of IP, RS, DGO and NFP, an announcement above the consensus is expected to have a positive impact on the stock market, whereas a CPI and a PPI higher than the consensus is expected to have a negative impact. Analogously, IP, RS, DGO, NFP below consensus are expected to be bad news for investors whereas a CPI and a PPI lower than forecasts are expected to have a positive impact.

The announcements under study are released on different days of the month and different days of the week. NFP is one of the indicators published by the Bureau of Labor Statistics in the Employment Report which is announced at the beginning of the month, usually on the first Friday. Hence, it is the earliest published indicator in the month of the indicators under study. The CPI, PPI, IP and RS are released in the middle of the month, around the 15th, by the Bureau of Labor Statistics, Federal Reserve and the Census Bureau of the Department of Commerce, respectively. DGO is announced the latest, around the 26th of the month. The majority of the announcements under study (167) were released on Fridays, mainly due to NFP announcements. However, when the other indicators are considered alone, the majority of the announcements (114) were released on Wednesdays. Because US macroeconomic data are released on different days of the month there are days when more than one announcement is released. In our dataset there are 71 such cases which are observed in the middle of the month. The most frequent are announcements on the same day about the IP and CPI (31 releases) and about PPI and RS (24 releases). Additionally, in two cases the CPI, IP and RS are announced on the same day. Only DGO and NFP are announced separately.

The sequence in which US macroeconomic indicator announcements are released may play an important role in the perception of them by investors. NFP is published first in the month among the indicators under study and it describes the condition of the US labor market in the previous month. This alone could attract investors' attention to it. On the other hand, when indicators are announced day by day their impact is weaker than when there is only one separate announcement. Thus, the impact of the CPI, PPI, IP and RS seems to be weaker than the impact of DGO and NFP. Another reason that supports this conjecture is the fact that indicator forecasts are published by Bloomberg a few days before the announcement and any news after that could change investor expectations and make forecasts out-of-date. Thus for some announcements the difference between the released value of an indicator and its consensus may be expected news.

When two or more indicators are announced on the same day, we consider only the first of them. Subsequent announcements on the same day are excluded from the sample because expectations about their value could be heavily influenced by earlier news. This is what is called the cofounding events problem. When two announcements are published at the same hour we take them into account only if they do not contain contradictory information, i.e. when both of them are good, or both of them are bad or 
one of them is in line with consensus. This allows us to avoid or at least to minimize the problem of confounding events. The final numbers of the different types of events under study that take place during trading days on the WSE are reported in Sect. 5 in Tables 1 and 2 together with results of the empirical study.

\subsection{Returns}

We investigate the impact of macroeconomic announcements on different types of stocks listed on the WSE and described by three indices, the WIG20, mWIG40 and sWIG80. The WIG20 is the index of the largest companies and is based on the value of a portfolio with the shares of the 20 major and most liquid companies (blue chips) on the WSE Main List. The mWIG40 index consists of medium-size companies and its value is computed on the basis of the stock prices of 40 medium size companies listed on the WSE Main List, while the sWIG80 is the small-firm index and it comprises 80 smaller companies listed on the WSE Main List. All computations in this paper are based on 1-min log-returns computed on the basis of intraday data between 1 April 2007 and 30 August 2013. The length of this period is due to changes in the quotations of the main indices on the WSE. Since April 2007 the WIG20 has been published every $15 \mathrm{~s}$ while the mWIG and sWIG are published every $60 \mathrm{~s}$ during trading sessions.

In the literature on intraday analysis it is common to use 5-min returns as a compromise between accuracy and the negative effects of market microstructure (e.g. Jones et al. 2005; Andersen et al. 2007; Harju and Hussain 2011). However, the problem of market microstructure noise is typical for stocks with low liquidity and should be of only minor importance when stock indices are examined. Moreover, the abovementioned literature confirms that the reaction of the stock market to important news releases occurs in the first $5 \mathrm{~min}$ after announcements or even earlier (Entorf and Steiner 2007). Hence, more frequent returns must be analyzed.

\subsection{Event study}

In the majority of the studies mentioned in the previous sections the response of stock returns to news announcements is examined via different kinds of regressions or autoregressions with additional sets of dummy variables corresponding to the news announcements examined (e.g. Flannery and Protopapadakis 2002; Jones et al. 2005; Andersen et al. 2007; Harju and Hussain 2011). Frequently, conditional volatility is also modeled by various ARCH-type models. In this approach the significance of the impact of news announcements is equivalent to the significance of the corresponding dummy variable. Generally, these regressions are performed on the basis of a whole sample of intraday returns. As well as standard model specification issues, this approach entails overcoming various other problems, like seasonal patterns in intraday volatility or the issue of overnight returns.

In this paper, however, we apply another way of testing stock price reactions to news announcements. To investigate the impact of US macroeconomic news on the intraday returns of WSE indices we use an event study methodology. This methodology is mainly applied to detect the effects of various news on daily returns data (e.g. Corrado 
and Truong 2008). In recent years, however, an event study has also been applied to intraday analysis (e.g. Dimpfl 2011).

In brief, an event study is the analysis of the significance of the abnormal behavior of returns around the event (i.e. in the so-called event window). The events in our study are defined as the unexpected macroeconomic news announcements described in Sect. 4.1. Abnormal returns are defined as the difference between actual returns and their expected values, i.e. for the $i$ th event and time $t$ they are given by the formula:

$$
A R_{i t}=R_{i t}-E\left(R_{i t} \mid \Omega_{t-1}\right)
$$

where $E\left(R_{i t} \mid \Omega_{t-1}\right)$ is the expectation of $R_{i t}$ conditional on information set $\Omega_{t-1}$ for time $t-1$. In practice, expected returns are computed from a model estimated on the basis of the returns from the pre-event window i.e. returns prior to the event window. The appropriate choice of pre-event and event windows is a crucial issue in the event study. The pre-event window should be as long as necessary to ensure suitable properties of the model estimates. On the other hand it must not include any other events (i.e. confounding events) that could influence returns and thus bias the results of the analysis. In this paper we use a pre-event window of length 130 (this means that it contains 1301 -min returns) and a 26-min event window. The event window consists of five returns before the event, the return at the time point of the news release and twenty 1-min returns after the announcement time. The majority of the news announcements under study are released at 14.30 CET. Hence, the pre-event window contains returns from 12.15 CET to 14.24 CET while the event window contains returns from 14.25 to 14.50. Even if we take into account the earliest announcements at 13.30 CET and the latest announcements at 15.15 CET the returns applied in the event study range at most from 11.15 CET to 15.35 CET. Until September 2008 continuous trading on the WSE used to take place from 9.30 to 16.10 . This means that the pre-event window starts at least $1 \mathrm{~h}$ and $45 \mathrm{~min}$ after the beginning of continuous trading on the WSE and the event window ends at least $35 \mathrm{~min}$ before the close of the trading session on the WSE. Thus, the intraday returns employed in this paper are from the middle of the trading session and the computations are not influenced by highly volatile returns at the beginning and at the end of a trading session. Moreover, because for each announcement we use only 1461 -min returns (i.e. less than $3 \mathrm{~h}$ ) from the middle of a trading session it is unnecessary to take into account intraday seasonality of returns.

To test the significance of the impact of macroeconomic news on WSE, i.e. to test the significance of mean abnormal returns in the event window, we apply the rank test of Corrado and Zivney (1992) with the correction of event-implied volatility. The advantage of this nonparametric test is that is does not need any assumption about the normality of abnormal returns and it has relatively high power when compared to other tests commonly used in event studies (Corrado 2011). The test statistics is constructed as follows.

If we denote the moment of a news release by $t=0$ then the pre-event window includes $t=-135, \ldots,-6$ while $t=-5, \ldots, 20$ constitute the event window. It should be noted here that the impact of the $i$ th news announcement can be observed 


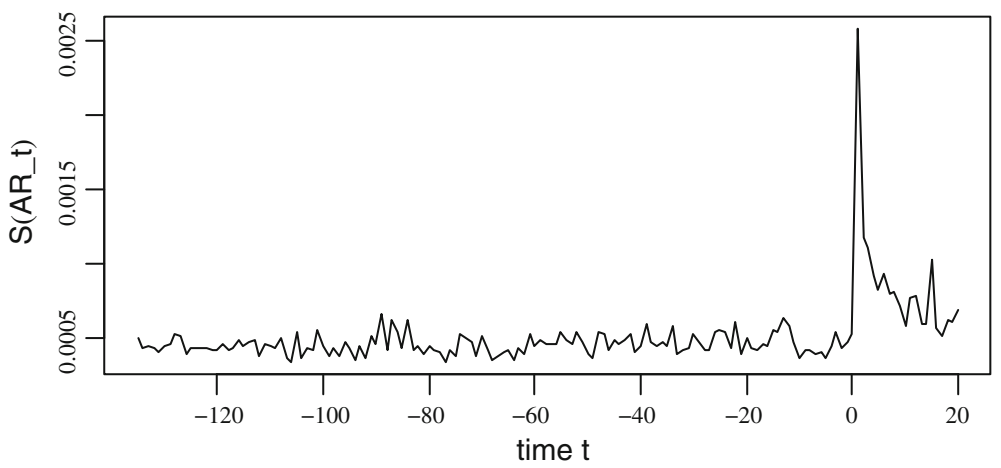

Fig. 1 Cross-sectional standard deviations of WIG20 abnormal returns (in \%) in the pre-event window and the event window (i.e. for $t=-135, \ldots, 20)$ when good news is announced (149 events in the cluster)

only for $t \geq 1$. When news is released at 14.30 then $R_{i 1}$ (return for $t=1$ ) is computed at 14.31 and describes the change in stock prices from 14.30 to 14.31 . For each $i$ th event in the cluster we fit an appropriate $\operatorname{ARMA}(p, q)$ model $^{4}$ to returns in the preevent window, and for $t=-135, \ldots, 20$, the abnormal return $A R_{i t}$ is defined as the difference between the actual return $R_{i t}$ and the one-step ARMA forecast. The application of the ARMA model instead of, for example, the constant mean model reduces significantly the autocorrelation in abnormal returns. Then, for each event, all abnormal returns in the event and pre-event windows are standardized:

$$
S A R_{i t}=A R_{i t} / S\left(A R_{i}\right)
$$

where

$$
S\left(A R_{i}\right)=\sqrt{\frac{1}{129} \sum_{t=-135}^{-6} A R_{i t}^{2}}
$$

is the standard deviation of abnormal returns in the pre-event window. In the practical analysis, however, increased volatility of abnormal returns is frequently observed in the event window (Corrado 2011; Corrado and Truong 2008). This phenomenon is also present in the case of the macroeconomic news announcements under study. As an example, Fig. 1 presents cross-sectional standard deviations of WIG20 abnormal returns in the pre-event and event windows when good news is announced. As can be noticed, abnormal returns volatility increases after the news release (for $t>0$ ) and is highest in the first minute. For $t \leq 0$ one can observe low variation. As mentioned earlier this is due to the fact that, in practice, $R_{i 0}$ i.e. the 1 -min return for $t=0$, is the last return before investors learn the news.

\footnotetext{
4 We consider all combinations of $p$ and $q$ for $p, q=1, \ldots, 5$. In the presence of heteroscedastisity in residuals we apply $A R M A(p, q)-G A R C H(1,1)$ model. We choose the appropriate ARMA model taking into account not only information criteria but also results of Ljung-Box tests for autocorrelations.
} 
To control for this event-induced change in the cross-sectional variance we adjust the standardized abnormal returns:

$$
S A R_{i t}^{\prime}= \begin{cases}S A R_{i t} & t=-135, \ldots, 0 \\ S A R_{i t} / S\left(S A R_{t}\right) & t=1, \ldots, 20\end{cases}
$$

where

$$
S\left(S A R_{t}\right)=\sqrt{\frac{1}{N-1} \sum_{i=1}^{N}\left(S A R_{i t}-\overline{S A R_{i t}}\right)^{2}}
$$

is the cross-sectional standard deviation of standardized abnormal returns and $N$ is the number of events in a cluster. We test the significance of abnormal returns for each $t_{0}$ in the event window separately. Thus for each $t_{0}=-5, \ldots, 20$ the Corrado-Zivney $T_{C Z}$ statistics is defined as in Corrado (2011):

$$
T_{C Z}\left(t_{0}\right)=\frac{1}{\sqrt{N}} \sum_{i=1}^{N} \frac{\left(\operatorname{rank}\left(S A R_{i t_{0}}^{\prime}\right)-\frac{n+1}{2}\right)}{\sqrt{n(n+1) / 12}}
$$

where $n$ is the length of the pre-event window (i.e. $n=130)$ and $\operatorname{rank}\left(\operatorname{SAR}_{i t_{0}}^{\prime}\right)$ denotes the rank of $S A R_{i t_{0}}^{\prime}$ within the vector consisting of standardized abnormal returns from the pre-event window and $S A R_{i t_{0}}^{\prime}$. The distribution of $T_{C Z}$ statistics converges rapidly to the standard normal distribution as the number of events $N$ increases.

\section{Empirical results}

The main assumption of the Corrado-Zivney test (and any other tests in the event study) is the independence of abnormal returns. When we fit an ARMA model to returns in the pre-event window we also perform the Ljung-Box portmanteau test and choose only a model with uncorrelated residuals. Thus abnormal returns are not autocorrelated. We do not have to check the abnormal returns for normality because the Corrado-Zivney test is a rank test.

In the first step of the study we examine the impact of each macroeconomic indicator separately. The findings are reported in Tables 1 and 2 for announcements below and above the consensus, respectively. The analysis of the reaction of the WIG20, mWIG40 and sWIG80 is presented in separate panels of Tables 1 and 2, while each column contains the means of the abnormal returns in the event window for specific macroeconomic indicator announcements. To save space we report $\overline{A R}_{t}$ only for the time very close to the announcement, i.e. for $t=-3, \ldots, 6$. This is the most important period of time just before and just after announcements when new information is incorporated into prices. As will be presented later (see Fig. 3) the impact of unexpected news weakens with time and there are almost no significant results for $t$ greater than 6. To facilitate the analysis of the event study results we also report the number of 
events in each cluster. The impact of a news release is described by the behavior of abnormal returns just after the news release. Thus, particular attention should be paid to the value and significance of $\overline{A R}_{1}$. However, when analyzing the results in Tables 1 and 2 we must take into account the sequence in which US macroeconomic indicators are announced during the month.

\subsection{Announcements below consensus}

The sign of mean abnormal returns in Table 1 for $t=1$ confirms that, irrespective of the index we examine, announcements of IP, DGO, RS and NFP below forecast are seen by investors as bad news while a CPI and a PPI below consensus are good news.

There are significantly negative reaction of the WIG20 in just the first minute after IP, DGO, RS and NFP announcements. However, IP, DGO and RS imply a significant reaction only in the first minute while the reaction to NFP announcements is significant also 2 min after the release. No other means of abnormal returns after the events are significant. The strongest reaction in the first minute after the announcement $\left(\overline{A R}_{1} \cong-0.26 \%\right)$ is induced by unexpected news from the US labor market included in NPF. In fact, this is the largest (in absolute value) mean abnormal return in the study. It also confirms the importance of information contained in the Employment Report (see Andersen et al. 2007) for the Polish stock market. These results for the WIG20 are in line with Conjectures 1 and 2.

The reaction of medium-sized firms listed on the $\mathrm{mWIG}$ is quite different from the reaction of the firms on the WIG20. Significant mean abnormal returns are observed not only in the first minutes after an announcement but also later, even up to 6 min after a news release. Such a longer reaction is visible especially for DGO and NFP. What is interesting is the fact that for the mWIG40 and sWIG80 the strongest reaction is not observed in the first minute after the release as it is for the WIG20. For example, when DGO is announced, then $\overline{A R}_{6}$ is the largest mean, while for NFP the largest is $\overline{A R}_{3}$. Moreover, $\overline{A R}_{1}$ is for the mWIG much closer to zero than $\overline{A R}_{1}$ is for the WIG20. This suggests that in the case of medium-sized firms unexpected negative information implies a weaker reaction and the news is more slowly incorporated into prices than in the case of large firms.

A slow reaction pattern and significant $\overline{A R}_{\mathrm{t}}$ for $t>1$ is also observed for the sWIG80. However, there are some differences between the reactions of the sWIG and the mWIG. The sWIG exhibits a significantly positive mean (at the $10 \%$ level) just after CPI announcements. This suggests that information about inflation in the US attracts the attention of small firm investors. The reaction of medium and big firms to CPI is not so evident because positive $\overline{A R}_{1}$ for the WIG20 and mWIG are not significant. The second difference is the lack of any significant reaction of small firms to news about RS. RS is a quite good example of differences in the reaction of the indices under study because its announcements imply a more and more delayed response of the indices: $\overline{A R}_{1}$ is significant for the WIG20, $\overline{A R}_{2}$ is significant for the mWIG40 and $\overline{A R}_{\mathrm{t}}$ are insignificant for the sWIG80. This also reflects the general rule that the stocks of small firms react in the first minutes after announcements only to the most common macroeconomic data, i.e. to news about inflation and unemployment. 
Table 1 Mean abnormal returns (in \%) of the WIG20, mWIG40, sWIG80 and WIG in the event window for US macroeconomic news announcements below forecasts (April 2007-August 2013)

Announcements below consensus

\begin{tabular}{|c|c|c|c|c|c|}
\hline $\begin{array}{l}\text { CPI } \\
(25 \text { events })\end{array}$ & $\begin{array}{l}\text { IP } \\
\text { (17 events) }\end{array}$ & $\begin{array}{l}\text { PPI } \\
\text { (27 events) }\end{array}$ & $\begin{array}{l}\text { DGO } \\
\text { (35 events) }\end{array}$ & $\begin{array}{l}\text { RS } \\
\text { (21 events) }\end{array}$ & $\begin{array}{l}\text { NFP } \\
\text { (36 events) }\end{array}$ \\
\hline
\end{tabular}

\begin{tabular}{|c|c|c|c|c|c|c|}
\hline \multicolumn{7}{|c|}{ WIG20 } \\
\hline-3 & -0.0176 & -0.0211 & 0.0061 & -0.0087 & -0.0023 & 0.0033 \\
\hline-2 & -0.0038 & 0.0098 & -0.0010 & $-0.0087^{*}$ & -0.0048 & 0.0095 \\
\hline-1 & -0.0159 & -0.0016 & 0.0038 & $-0.0146^{* *}$ & -0.0105 & 0.0087 \\
\hline 0 & -0.0071 & 0.0014 & 0.0003 & 0.0098 & 0.0098 & -0.0049 \\
\hline 1 & 0.0788 & $-0.0400 * *$ & 0.0093 & $-0.1625^{* * *}$ & $-0.1380 * *$ & $-0.2576^{* * * *}$ \\
\hline 2 & 0.0459 & -0.0187 & 0.0360 & -0.0042 & -0.0358 & $-0.0422^{*}$ \\
\hline 3 & -0.0091 & -0.0106 & 0.0088 & -0.0123 & 0.0087 & -0.0134 \\
\hline 4 & -0.0192 & 0.0014 & 0.0021 & -0.0001 & 0.0070 & 0.0475 \\
\hline 5 & 0.0255 & 0.0007 & -0.0027 & 0.0006 & -0.0359 & 0.0173 \\
\hline 6 & 0.0153 & 0.0334 & -0.0045 & -0.0083 & -0.0061 & 0.0059 \\
\hline \multicolumn{7}{|c|}{$m W I G 40$} \\
\hline-3 & -0.0002 & -0.0063 & -0.0068 & 0.0015 & -0.0044 & 0.0009 \\
\hline-2 & $0.0067^{* *}$ & -0.0059 & -0.0124 & 0.0039 & -0.0031 & 0.0029 \\
\hline-1 & -0.0009 & 0.0102 & 0.0059 & -0.0005 & -0.0035 & 0.0020 \\
\hline 0 & 0.0009 & 0.0005 & -0.0062 & -0.0067 & -0.0023 & -0.0060 \\
\hline 1 & 0.0027 & 0.0010 & 0.0034 & $-0.0075^{* *}$ & -0.0118 & $-0.0096^{* * *}$ \\
\hline 2 & 0.0040 & -0.0005 & 0.0079 & -0.0043 & $-0.0179 * *$ & -0.0049 \\
\hline 3 & -0.0016 & -0.0032 & 0.0056 & $-0.0132 * *$ & 0.0041 & $-0.0216^{* * * *}$ \\
\hline 4 & 0.0013 & -0.0064 & 0.0085 & $-0.0086^{* * *} *$ & -0.0065 & -0.0019 \\
\hline 5 & 0.0121 & 0.0024 & $0.0081 * *$ & -0.0070 & -0.0075 & 0.0019 \\
\hline 6 & 0.0056 & 0.0100 & 0.0026 & $-0.0140^{* * * *}$ & $-0.0191 * * *$ & $-0.0129 * * *$ \\
\hline \multicolumn{7}{|c|}{ sWIG80 } \\
\hline-3 & 0.0013 & 0.0021 & -0.0051 & -0.0048 & -0.0045 & 0.0000 \\
\hline-2 & $0.0106^{* *}$ & -0.0004 & $-0.0011^{*}$ & -0.0040 & 0.0011 & $-0.0050 * *$ \\
\hline-1 & 0.0026 & -0.0049 & 0.0085 & 0.0016 & $-0.0135^{* *}$ & -0.0029 \\
\hline 0 & -0.0009 & 0.0040 & -0.0042 & 0.0028 & 0.0006 & 0.0024 \\
\hline 1 & $0.0036^{*}$ & 0.0000 & 0.0045 & -0.0010 & -0.0074 & $-0.0091 * * *$ \\
\hline 2 & -0.0012 & -0.0064 & $0.0109 * *$ & -0.0068 & -0.0019 & $-0.0266^{* * *}$ \\
\hline 3 & -0.0065 & 0.0101 & 0.0017 & $-0.0092^{* *}$ & -0.0127 & -0.0049 \\
\hline 4 & $0.0050 *$ & 0.0024 & 0.0023 & $-0.0082^{*}$ & -0.0025 & $-0.0122 * *$ \\
\hline 5 & -0.0001 & -0.0020 & 0.0050 & -0.0017 & 0.0017 & -0.0045 \\
\hline 6 & 0.0038 & 0.0047 & 0.0066 & 0.0004 & -0.0072 & -0.0019 \\
\hline \multicolumn{7}{|c|}{$W I G$} \\
\hline-3 & -0.0047 & -0.0069 & -0.0019 & -0.0024 & -0.0015 & -0.0008 \\
\hline-2 & -0.0046 & 0.0025 & -0.0090 & $-0.0042^{*}$ & -0.0045 & 0.0017 \\
\hline-1 & -0.0099 & -0.0008 & 0.0065 & -0.0039 & -0.0050 & 0.0077 \\
\hline 0 & -0.0023 & 0.0027 & -0.0098 & -0.0063 & 0.0036 & $-0.0251 * *$ \\
\hline
\end{tabular}


Table 1 continued

\begin{tabular}{lllllll}
\hline \multicolumn{5}{c}{ Announcements below consensus } & & \\
\cline { 2 - 6 } & $\begin{array}{l}\text { CPI } \\
(25 \text { events })\end{array}$ & $\begin{array}{l}\text { IP } \\
(17 \text { events })\end{array}$ & $\begin{array}{l}\text { PPI } \\
(27 \text { events })\end{array}$ & $\begin{array}{l}\text { DGO } \\
(35 \text { events })\end{array}$ & $\begin{array}{l}\text { RS } \\
(21 \text { events })\end{array}$ & $\begin{array}{l}\text { NFP } \\
(36 \text { events })\end{array}$ \\
\hline 1 & 0.0611 & $-0.0285^{* * *}$ & 0.0197 & $-0.1005 * * *$ & $-0.0935^{* *}$ & $-0.1608^{* * *}$ \\
2 & 0.0246 & -0.0133 & $0.0317 * *$ & 0.0031 & -0.0148 & $-0.0098^{*}$ \\
3 & $-0.0285^{* *}$ & -0.0126 & 0.0048 & $-0.0135^{* * *}$ & -0.0095 & -0.0022 \\
4 & -0.0109 & 0.0013 & 0.0049 & 0.0035 & 0.0162 & -0.0003 \\
5 & 0.0221 & $0.0097 * *$ & -0.0019 & -0.0041 & -0.0221 & 0.0142 \\
6 & 0.0010 & $0.0180^{* *}$ & -0.0057 & -0.0054 & -0.0128 & -0.0071 \\
\hline
\end{tabular}

$*, * *, * * *$ Significance at 10,5 and $1 \%$, respectively

Another difference between the returns of the sWIG80 and the returns of larger stocks are significant means before announcements (CPI, PPI, RS and NFP). This particular behavior of sWIG80 returns is probably caused by the larger number of individual and small investors.

All the stocks from the WIG20, mWIG and sWIG are included in the WIG which describes the whole WSE. Its reaction to new information is a combination of the reactions of these indices. Stocks from the WIG20 constitute about $70 \%$ of the WIG. Hence WIG returns react significantly just after IP, DGO, RS and NFP announcements. However, the reaction of medium-sized and small companies is not limited to the first minute after news releases. Stocks from the $\mathrm{mWIG}$ and SWIG are probably also responsible for significant $\overline{A R}_{t}$ after news about inflation. However, it should be noted here that when a CPI is below consensus $\overline{A R}_{3}$ is significantly negative, which suggests a significant counter reaction.

As with the WIG20 there is almost no significant reaction of the WIG before a news release. An important exception is a negative mean abnormal return just before NFP announcements.

\subsection{Announcements above consensus}

Our findings within the framework of the event study for announcements above forecasts are summarized in Table 2. Analogously to Table 1, announcements of IP, DGO, RS and NFP greater than expected are seen to be good news and lead to positive means of abnormal returns. On the other hand, inflation greater than forecast is seen as bad news. As before, the WIG20 reacts mainly in the first minute after a news release.

However, significant means are also observed for $t>1$ (PPI, DGO and RS). For CPI, PPI and NFP we observe significant (at the 5 and $10 \%$ level) mean abnormal returns before the event. Similarly to Table 1 , the strongest reaction measured by $\overline{A R}_{1}$ occurs when NFP is announced $\left(\overline{A R}_{1} \cong 0.18 \%\right)$. There is an interesting reaction pattern when PPI is announced. PPI greater than expected causes negative investor reactions in the first minute $\left(\overline{A R}_{1} \cong-0.1 \%\right)$ which are, however, followed by a significantly positive change in the next minute $\left(\overline{A R}_{2} \cong 0.04 \%\right)$. The reaction of the 
Table 2 Mean abnormal returns (in \%) of WIG20, mWIG40, sWIG80 and WIG in the event window for US macroeconomic news announcements above previous forecasts (April 2007-August 2013)

Announcements above consensus

\begin{tabular}{|c|c|c|c|c|c|}
\hline $\begin{array}{l}\text { CPI } \\
(21 \text { events })\end{array}$ & $\begin{array}{l}\text { IP } \\
\text { (8 events) }\end{array}$ & $\begin{array}{l}\text { PPI } \\
\text { (29 events) }\end{array}$ & $\begin{array}{l}\text { DGO } \\
\text { (35 events) }\end{array}$ & $\begin{array}{l}\text { RS } \\
\text { (23 events) }\end{array}$ & $\begin{array}{l}\text { NFP } \\
\text { (31 events) }\end{array}$ \\
\hline
\end{tabular}

\begin{tabular}{|c|c|c|c|c|c|c|}
\hline \multicolumn{7}{|c|}{ WIG20 } \\
\hline-3 & -0.0071 & -0.0173 & 0.0050 & 0.0028 & 0.0061 & -0.0002 \\
\hline-2 & 0.0085 & 0.0210 & -0.0100 & 0.0080 & 0.0093 & 0.0009 \\
\hline-1 & $0.0113^{*}$ & 0.0073 & $-0.0122 *$ & -0.0022 & 0.0054 & 0.0096 \\
\hline 0 & -0.0126 & 0.0046 & -0.0002 & 0.0035 & -0.0052 & $-0.0137 * *$ \\
\hline 1 & -0.0937 & 0.1103 & $-0.1022^{* *}$ & $0.1140 * * *$ & $0.1299 * * *$ & $0.1768 * * *$ \\
\hline 2 & -0.0332 & 0.0168 & $0.0413^{*}$ & 0.0107 & 0.0318 & 0.0313 \\
\hline 3 & 0.0185 & 0.0882 & 0.0347 & $0.0354 *$ & $0.0361 * *$ & 0.0138 \\
\hline 4 & 0.0026 & 0.0176 & -0.0165 & 0.0120 & 0.0089 & 0.0077 \\
\hline 5 & -0.0375 & -0.0053 & -0.0253 & 0.0033 & 0.0021 & -0.0078 \\
\hline 6 & -0.0001 & $-0.0431^{* *}$ & $0.0434 * *$ & 0.0108 & 0.0008 & -0.0092 \\
\hline \multicolumn{7}{|c|}{$m W I G 40$} \\
\hline-3 & -0.0049 & 0.0042 & 0.0076 & 0.0013 & -0.0024 & -0.0048 \\
\hline-2 & 0.0037 & -0.0229 & -0.0092 & -0.0047 & -0.0017 & $-0.0055^{* *}$ \\
\hline-1 & -0.0063 & 0.0009 & $-0.0107 *$ & $0.0076^{*}$ & -0.0024 & 0.0076 \\
\hline 0 & $-0.0090^{* *}$ & 0.0016 & -0.0024 & 0.0041 & 0.0008 & 0.0015 \\
\hline 1 & -0.0089 & 0.0061 & 0.0038 & $0.0087 *$ & 0.0069 & 0.0114 \\
\hline 2 & $-0.0165^{*}$ & 0.0119 & 0.0009 & -0.0028 & 0.0067 & 0.0026 \\
\hline 3 & -0.0003 & -0.0013 & -0.0019 & -0.0010 & $0.0052 * *$ & 0.0075 \\
\hline 4 & -0.0058 & 0.0069 & -0.0075 & -0.0068 & -0.0011 & 0.0067 \\
\hline 5 & 0.0004 & 0.0137 & 0.0064 & $0.0097 * *$ & 0.0031 & 0.0006 \\
\hline 6 & -0.0141 & $0.0224 * * *$ & 0.0000 & $0.0055^{* *}$ & 0.0013 & -0.0060 \\
\hline \multicolumn{7}{|c|}{ sWIG80 } \\
\hline-3 & 0.0026 & 0.0041 & 0.0030 & -0.0009 & 0.0120 & 0.0053 \\
\hline-2 & -0.0046 & -0.0114 & -0.0027 & 0.0014 & -0.0011 & -0.0003 \\
\hline-1 & $0.0088 * *$ & -0.0074 & 0.0074 & 0.0005 & -0.0049 & 0.0027 \\
\hline 0 & -0.0020 & $0.0192 * * *$ & -0.0041 & 0.0013 & 0.0005 & -0.0112 \\
\hline 1 & $-0.0083^{*}$ & 0.0052 & -0.0034 & $0.0050 * *$ & 0.0023 & 0.0043 \\
\hline 2 & -0.0054 & 0.0051 & -0.0041 & 0.0009 & 0.0062 & 0.0038 \\
\hline 3 & -0.0048 & 0.0074 & -0.0045 & 0.0005 & $0.0122 *$ & -0.0065 \\
\hline 4 & -0.0051 & 0.0010 & 0.0001 & 0.0040 & 0.0049 & 0.0048 \\
\hline 5 & 0.0060 & 0.0019 & -0.0028 & 0.0019 & -0.0008 & 0.0024 \\
\hline 6 & $-0.0083^{* *}$ & 0.0098 & -0.0077 & 0.0056 & 0.0126 & 0.0014 \\
\hline \multicolumn{7}{|c|}{$W I G$} \\
\hline-3 & 0.0036 & 0.0108 & -0.0012 & $0.0059 * *$ & 0.0046 & -0.0019 \\
\hline-2 & -0.0012 & -0.0029 & -0.0118 & -0.0015 & $0.0099 * *$ & -0.0002 \\
\hline-1 & -0.0014 & 0.0037 & -0.0024 & 0.0069 & -0.0025 & 0.0061 \\
\hline
\end{tabular}


Table 2 continued

\begin{tabular}{|c|c|c|c|c|c|c|}
\hline & \multicolumn{6}{|c|}{ Announcements above consensus } \\
\hline & $\begin{array}{l}\text { CPI } \\
\text { (21 events) }\end{array}$ & $\begin{array}{l}\text { IP } \\
\text { (8 events) }\end{array}$ & $\begin{array}{l}\text { PPI } \\
\text { (29 events) }\end{array}$ & $\begin{array}{l}\text { DGO } \\
\text { (35 events) }\end{array}$ & $\begin{array}{l}\text { RS } \\
\text { (23 events) }\end{array}$ & $\begin{array}{l}\text { NFP } \\
\text { (31 events) }\end{array}$ \\
\hline 0 & -0.0020 & 0.0075 & -0.0064 & 0.0005 & -0.0039 & 0.0065 \\
\hline 1 & -0.0820 & $0.0814^{* *}$ & $-0.0633 * *$ & $0.0812 * * *$ & $0.0943 * * *$ & $0.1084^{* *}$ \\
\hline 2 & -0.0039 & 0.0097 & $0.0449 * *$ & 0.0059 & 0.0186 & 0.0062 \\
\hline 3 & 0.0029 & 0.0335 & -0.0006 & $0.0220^{*}$ & $0.0309 * * *$ & 0.0217 \\
\hline 4 & -0.0044 & 0.0125 & -0.0096 & 0.0035 & -0.0058 & -0.0050 \\
\hline 5 & -0.0269 & 0.0081 & 0.0083 & 0.0115 & 0.0058 & -0.0031 \\
\hline 6 & 0.0129 & -0.0065 & 0.0050 & 0.0015 & -0.0032 & -0.0025 \\
\hline
\end{tabular}

mWIG just after the event is weaker than that of the WIG20. Only $\overline{A R}_{1}$ for DGO news is significant at the $10 \%$ level. For the other indices, significant means are observed later, if at all. Similar insignificant reactions to good news can be noticed in the case of the sWIG80. In first minute after the event, the only positive $\overline{A R}_{1}$ is for DGO. As we see, the results for announcements above the consensus are also mostly in line with Conjectures 1, 2 and 3.

The WIG mainly reflects the behavior of the WIG20, i.e. a significant reaction is observed only in the first $3 \mathrm{~min}$ after a news release. In addition, with respect to the WIG20, $\overline{A R}_{1}$ for IP is also significant.

\subsection{Good and bad news}

As mentioned in Sect. 3, we divide all announcements into the two clusters of good and bad news on the basis of the results in Tables 1 and 2. The good news cluster contains CPI and PPI announcements below forecast and IP, DGO, RS and NFP announcements above forecast, while the bad news cluster contains CPI and PPI announcements above forecast and IP, DGO, RS and NFP below forecast. The results of the event study analysis for these two clusters are reported in Tables 3 and 4, respectively. For each index we report mean abnormal returns and rank test statistics $T_{C Z}$ for $t=-3, \ldots, 6$.

In general, there is no significant change in stock prices before the announcements. The only exceptions are the $\overline{A R}_{-2}$ 's of the sWIG and the WIG which are significant at the 5 and $10 \%$ levels, respectively, and $\overline{A R}_{0}$ for the WIG which is significant at the $10 \%$ level. The most important are the highly significant means of the abnormal return for all indices just after the announcement. Each index reacts significantly negatively to bad news in the first minute. The strongest reaction is visible for the WIG20 $\left(\overline{A R}_{1} \cong-0.15 \%\right)$ and is also reflected in WIG abnormal returns $\left(\overline{A R}_{1} \cong-0.096 \%\right)$. This immediate and sharp decline in the stock prices of the largest firms disappears very quickly and the following means are insignificant. The reactions of the mWIG and the sWIG are lower in magnitude, but the mean abnormal returns are significantly negative even up to $6 \mathrm{~min}$ after a news release. This is in line with previous results for 
Table 3 Mean abnormal returns (in \%) and $T_{C Z}$ rank test statistics of WIG20, mWIG40, sWIG80 and WIG in the event window for "bad news"

\begin{tabular}{|c|c|c|c|c|c|c|c|c|}
\hline & \multicolumn{2}{|l|}{ WIG20 } & \multicolumn{2}{|l|}{ mWIG } & \multicolumn{2}{|l|}{ sWIG } & \multicolumn{2}{|l|}{ WIG } \\
\hline & $\overline{A R}_{t}$ & $T_{C Z}$ & $\overline{A R}_{t}$ & $T_{C Z}$ & $\overline{A R}_{t}$ & $T_{C Z}$ & $\overline{A R}_{t}$ & $T_{C Z}$ \\
\hline-3 & -0.0038 & -0.03 & 0.0000 & 0.27 & -0.0005 & 0.54 & -0.0014 & -0.42 \\
\hline-2 & -0.0001 & -0.12 & -0.0007 & -0.44 & $-0.0030 * *$ & -2.21 & $-0.0032 *$ & -1.79 \\
\hline-1 & -0.0035 & -1.11 & -0.0018 & -0.39 & -0.0001 & 1.00 & -0.0005 & -0.28 \\
\hline 0 & 0.0008 & -0.53 & -0.0047 & -1.50 & 0.0007 & 0.58 & $-0.0077^{*}$ & -1.68 \\
\hline 1 & $-0.1476^{* * * *}$ & -6.81 & $-0.0058 * * *$ & -2.85 & $-0.0050^{* * * *}$ & -2.90 & $-0.0963 * * *$ & -6.41 \\
\hline 2 & -0.0141 & -1.24 & $-0.0065^{* * *}$ & -3.45 & $-0.0099 * * *$ & -4.73 & 0.0028 & -0.45 \\
\hline 3 & 0.0030 & -0.21 & $-0.0080 * * *$ & -3.07 & $-0.0052^{* *}$ & -2.06 & $-0.0058^{* *}$ & -2.09 \\
\hline 4 & 0.0092 & 0.49 & $-0.0060 * * *$ & -2.98 & $-0.0053^{* *}$ & -2.55 & 0.0007 & -0.11 \\
\hline 5 & -0.0102 & -0.68 & -0.0006 & 0.78 & -0.0011 & -0.54 & -0.0016 & 0.37 \\
\hline 6 & 0.0102 & 1.30 & $-0.0093 * * *$ & -3.87 & -0.0033 & -1.15 & 0.0000 & 0.19 \\
\hline
\end{tabular}

159 events from April 2007 to August 2013

$*, * *, * * *$ Significance at 10,5 and $1 \%$, respectively

Table 4 Mean abnormal returns (in \%) and $T_{C Z}$ rank test statistics of WIG20, mWIG40, sWIG80 and WIG in the event window for "good news"

\begin{tabular}{|c|c|c|c|c|c|c|c|c|}
\hline & \multicolumn{2}{|l|}{ WIG20 } & \multicolumn{2}{|l|}{ mWIG } & \multicolumn{2}{|l|}{ sWIG } & \multicolumn{2}{|l|}{ WIG } \\
\hline & $\overline{A R}_{t}$ & $T_{C Z}$ & $\overline{A R}_{t}$ & $T_{C Z}$ & $\overline{A R}_{t}$ & $T_{C Z}$ & $\overline{A R}_{t}$ & $T_{C Z}$ \\
\hline-3 & -0.0012 & 0.29 & -0.0021 & -1.19 & 0.0023 & 0.90 & 0.0011 & 0.78 \\
\hline-2 & $0.0038^{*}$ & 1.74 & -0.0049 & -0.83 & $0.0010^{*}$ & 1.95 & -0.0014 & 0.30 \\
\hline-1 & 0.0007 & -0.52 & 0.0040 & 1.33 & 0.0015 & 0.74 & 0.0022 & 0.71 \\
\hline 0 & -0.0037 & -1.35 & 0.0005 & 0.46 & -0.0018 & 0.14 & -0.0009 & -0.10 \\
\hline 1 & $0.1044 * * *$ & 5.06 & $0.0069 * *$ & 2.04 & $0.0041 * * *$ & 3.42 & $0.0744 * * *$ & 4.95 \\
\hline 2 & $0.0291 * * *$ & 2.59 & 0.0037 & 1.55 & $0.0040 * * *$ & 3.01 & $0.0159 * * *$ & 2.64 \\
\hline 3 & $0.0216^{*}$ & 1.89 & $0.0028 * *$ & 2.24 & $0.0003^{*}$ & 1.76 & 0.0123 & 1.05 \\
\hline 4 & 0.0039 & -0.24 & $0.0017^{*}$ & 1.76 & $0.0040^{* * *}$ & 3.18 & -0.0014 & -1.19 \\
\hline 5 & 0.0030 & -0.37 & $0.0071 * * *$ & 2.83 & 0.0018 & 1.22 & 0.0068 & 0.76 \\
\hline 6 & 0.0002 & 0.56 & $0.0029 * *$ & 2.10 & $0.0059^{* *}$ & 2.27 & -0.0019 & -0.37 \\
\hline
\end{tabular}

149 events from April 2007 to August 2013

$*, * *, * * *$ Significance at 10,5 and $1 \%$, respectively

individual macroeconomic indicators. The reaction of WSE indices to good news is similar. There is almost no significant $\overline{A R}_{t}$ before the event. The significant reaction starts at $t=1$. The WIG20 has three significantly positive mean abnormal returns while the reaction of the $\mathrm{mWIG}$ and sWIG is much longer. The results presented in this subsection for good and bad news clusters also support Conjectures 1, 2, 3 .

We use Bloomberg consensus as a measure of the forecasted value of the announced indicator. This consensus, however, may not always reflect actual investors' expectations because it is published a few days before announcements. Thus, we also examine 
the reactions of the WSE indices to the announcements in line with the consensus. The abnormal returns of all indices under study induced by these "neutral" announcements are insignificant in the event window. It means that the announcements in line with the consensus do not impact the WSE indices.

\subsection{Comparison of the reactions to bad and good news}

The comparison of the means of abnormal returns in Tables 1 and 2 suggests that bad news induce a stronger reaction of WSE indices in the first minute after a news release. To verify this conjecture for each macroeconomic indicator and for each index of WSE we compare abnormal returns in clusters 'above consensus' and 'below consensus'. However, abnormal returns in these clusters differ because one of them contains good news with a positive mean of abnormal returns, whereas the other contains bad news with a negative mean. Thus we multiply abnormal returns in one of the clusters by -1 . As an example, Fig. 2 presents box-plots of $A R_{1}$ for good news and $-A R_{1}$ for bad news clusters. We see that the differences between means (or medians) in both clusters are not so significant when compared to the variation of abnormal returns in each cluster.

As mentioned previously, abnormal returns are not normally distributed. Thus we use nonparametric Kruskal-Wallis test to test the significance of the difference between the strength of the returns' reaction to bad and good news measured as the deviation of abnormal returns from zero. The null hypothesis in this test is that abnormal returns for $t=1$ in opposite clusters have the same distribution. We do not report details of these results here because for any index of the WSE and for any macroeconomic indicator the null hypothesis cannot be rejected even at the $10 \%$ significance level. These results indicate that there is no significant difference between the reaction of the WSE indices to good and bad news contained in US macroeconomic announcements. Hence the reaction can be seen as symmetric. This contradicts Conjecture 4 .

As above, we also compare whether the reactions of the WIG20, mWIG40 and sWIG80 differ in the first minute after any given macroeconomic indicator announcement. The results in Tables 1 and 2 suggest that such a conjecture is reasonable. To

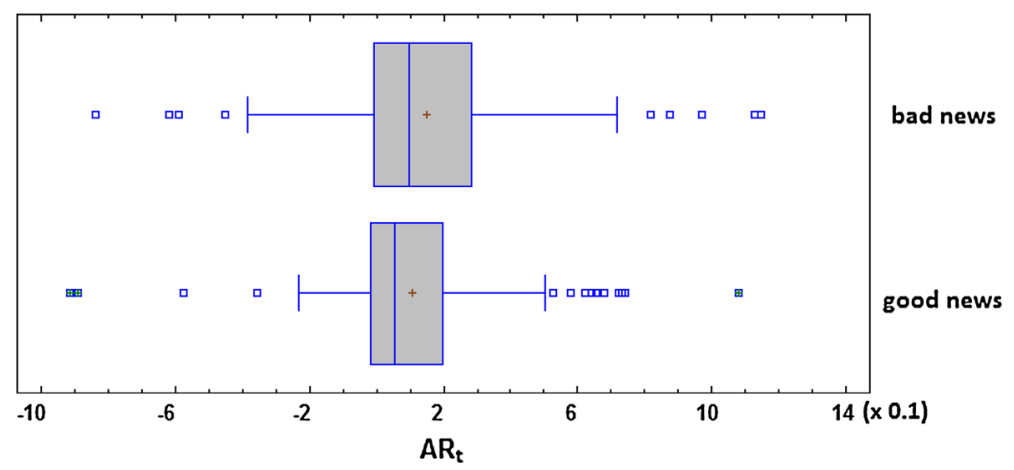

Fig. 2 Box-and-whisker plots of $A R_{1}$ (in \%) in the "good news" cluster and $-A R_{1}$ (in \%) in the "bad news" cluster for the WIG20 
Table 5 Comparison of WSE index reactions to different kinds of announcements

\begin{tabular}{|c|c|c|c|c|}
\hline & \multicolumn{2}{|c|}{ Below consensus } & \multicolumn{2}{|c|}{ Above consensus } \\
\hline & KW & $p$ value & KW & $p$ value \\
\hline CPI & 1.59 & 0.451 & 0.68 & 0.710 \\
\hline IP & 4.92 & 0.085 & 4.61 & 0.100 \\
\hline PPI & 0.66 & 0.720 & 2.87 & 0.238 \\
\hline DGO & 23.2 & $9 \times 10^{-9}$ & 13.0 & 0.002 \\
\hline RS & 6.66 & 0.036 & 10.7 & 0.005 \\
\hline \multirow[t]{2}{*}{ NFP } & 24.1 & $6 \times 10^{-6}$ & 13.3 & 0.001 \\
\hline & \multicolumn{2}{|c|}{ Bad news } & \multicolumn{2}{|c|}{ Good news } \\
\hline All & 49.36 & $2 \times 10^{-11}$ & 37.88 & $6 \times 10^{-9}$ \\
\hline
\end{tabular}

verify the significance of the differences between the distribution of $A R_{1}$ for the WSE indices in each cluster we apply the Kruskal-Wallis test. The results of the testing procedure are summarized in Table 5. For each US macroeconomic indicator and for each cluster (below or above consensus) we report the value of Kruskal-Wallis statistics $(\mathrm{KW})$ with a corresponding $p$ value. Additionally, we report the results of the Kruskal-Wallis test for all good or bad news. It can be noticed that the returns of the WSE indices react significantly differently (at the $1 \%$ level) to DGO and NFP announcements irrespective of their values and of the announced value of RS being greater than expected. The reaction to announcements of RS below forecast is significant at the $5 \%$ level. The null hypothesis about the equality of distributions of all indices' abnormal returns 1 min after good or after bad news is also rejected at each commonly-used significance level. This confirms the observations made on the basis of the results in Tables 1 and 2 that WSE indices react significantly differently to some US macroeconomic announcements. In general, this is mainly due to the immediate and very strong reaction of the WIG20.

Not only the size of the abnormal returns caused by macroeconomic announcements is important, but also the duration of the response of financial markets to news releases. This problem is highlighted in the next subsection.

\subsection{Duration of impact}

In view of the above results it is reasonable to study the differences in the reaction patterns of WSE indices to US macroeconomic news announcements. To describe the duration and the strength of index reactions we compare their cumulative mean abnormal returns (CUM_AR) for the first $20 \mathrm{~min}$ after a news release. To make the comparison of the reaction to good and bad news easier we multiply the cumulative mean abnormal returns for the release of bad news by -1 . The top panel of Fig. 3 illustrates the strong and immediate reaction of the WIG20 which takes place at most in the first $3 \mathrm{~min}$ after the event. After this time the graph of cumulative mean abnormal returns is almost horizontal and for $t>4$ there are almost no abnormal changes in the WIG20. This is in line with the results in Tables 3 and 4 where there is only one 

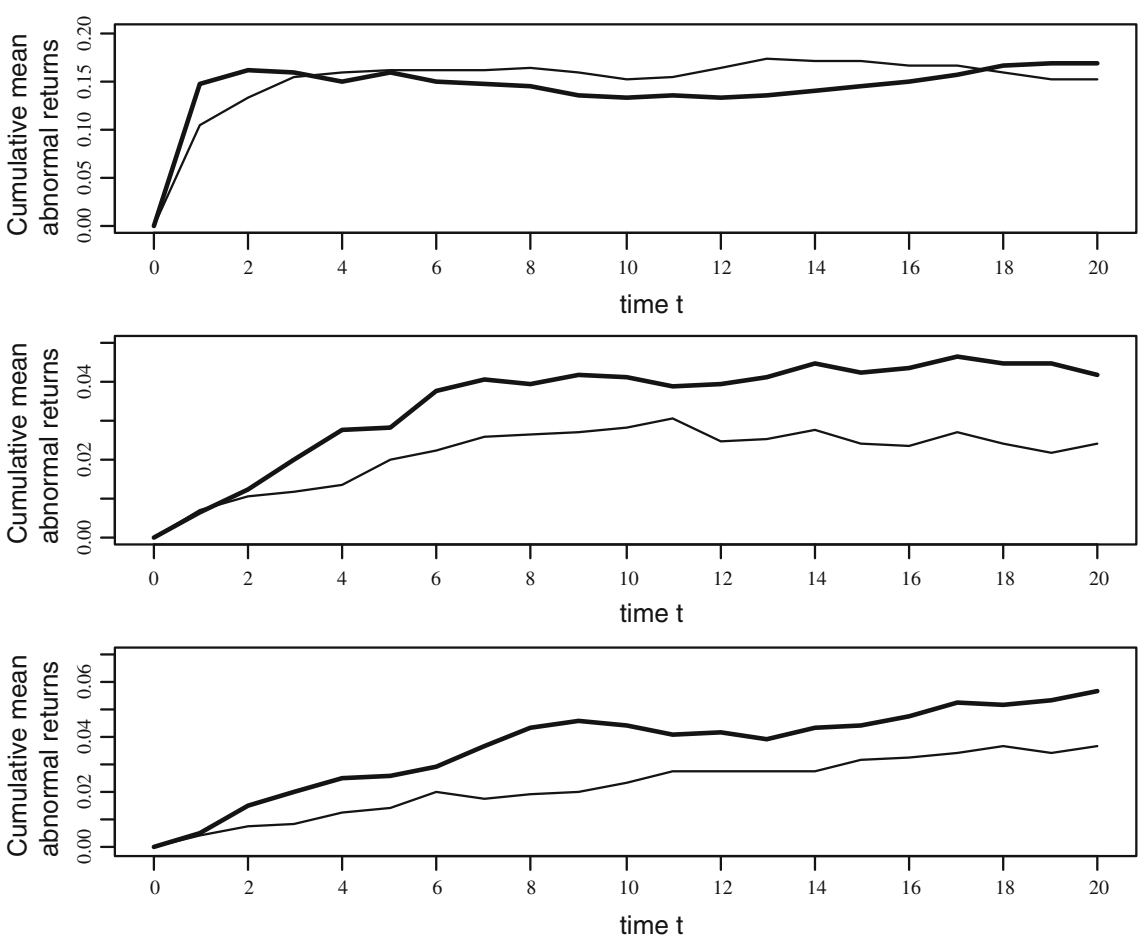

Fig. 3 Cumulative mean abnormal returns of the WIG20 (top panel), mWIG40 (middle panel) and sWIG80 (bottom panel). The thin line indicates CUM_AR after good news while the thick line describes minus CUM_AR after bad news releases

significant mean abnormal return when bad news is announced, and three significant $\overline{A R}_{t}$ after a release of good news. The reaction to positive news (thin line) seems to be slower than to bad news (thick line), but Mann-Whitney tests show no statistical difference between the cumulative abnormal returns of the WIG20 for any $t>0$. The middle panel of Fig. 3 confirms previous results indicating that the reaction of the $\mathrm{mWIG}$ is much slower than that of the WIG20. The cumulative impact of unexpected news slowly increases up to 7-8 min, where it stabilizes. As above, there are no significant differences between the total effect of bad news (thick line) and good news (thin line) in the event window. The impact of unexpected news on the sWIG80 is visible in the whole first $20 \mathrm{~min}$ after the release. Cumulative means slowly increase for $t>0$. As for the WIG20 and mWIG40, the cumulative effect of bad news does not differ significantly from the cumulative effect of good news.

When we compare the reaction of each index to that of the others we can observe that the total effect of unexpected news is strongest for the WIG20 where the cumulative mean abnormal returns after $20 \mathrm{~min}$ are about $0.16 \%$, which is much higher than the 0.035 and $0.05 \%$ for the mWIG40 and the sWIG80, respectively. In fact, almost the whole value $0.16 \%$ of the cumulative mean abnormal returns of the WIG 20 is achieved in the first $3 \mathrm{~min}$.

In the final section we summarize the main findings of this empirical study. 


\section{Conclusions}

In this paper we examine the impact of US macroeconomic data announcements on indices of the Warsaw Stock Exchange from April 2007 to August 2013. We study the impact of the six following indicators: the Consumer Price Index, Industrial Production, the Producer Price Index, Durable Goods Orders, Retail Sales and Nonfarm Payrolls. Three indices, namely the WIG20, mWIG40 and sWIG80 describe the behavior of the stocks of large, medium-sized and small firms listed on the WSE. To examine the impact of US announcements we apply an event study to 1-min returns of the above indices.

The analysis in the paper confirms that announcements of a CPI and PPI below forecast and announcements of DGO, RS, IP and NFP above forecast are seen as good news by investors on the WSE, and vice versa, that a CPI and a PPI above the consensus and DGO, RS, IP and NFP below the consensus are seen as bad news. Good news imply positive abnormal returns of the WSE indices after announcements whereas bad news imply negative abnormal returns after announcements. In the first minute after a news release the WIG20 reacts significantly to IP, DGO, RS and NFP announcements below the consensus and to PPI, DGO, RS and NFP above the consensus. The strongest reaction is induced by news about NFP $(-0.258$ and $0.177 \%$ for announcements below and above the consensus, respectively). The impact of US data on the mWIG40 and sWIG80 is not so easy to interpret. The index mWIG40 reacts to PPI, DGO, RS and NFP announcements below the consensus and to PPI and NFP above the consensus. Significant abnormal returns of the sWIG80 are observed after announcements of CPI, PPI, DGO and NFP lower than forecasted and of IP, PPI, NFP greater than forecasted. Hence, each kind of announcement induces a reaction of at least one index on the WSE. The significant and very quick reaction of WSE indices to US macroeconomic data announcements is in line with previous results for developed markets.

When all announcements are divided into two clusters: "bad news" and "good news", all indices react significantly in the first minute after a news release. This indicates the high efficiency of the WSE. The strength and duration of the reaction differs between indices. Significant mean abnormal returns of the WIG20 are observed only in the first minute after bad news and in the first 3 min after good news. After that the abnormal returns of the WIG20 are insignificant. The reactions of the mWIG40 and sWIG80 are weaker and slower than that of the WIG20. This result confirms the speed of adjustment hypothesis.

The reaction of the WIG20 is also the strongest. Good news implies $0.1 \%$ abnormal change in WIG20 while bad news implies about $-0.15 \%$ change in the WIG20 in the first minute after the announcements. However, performed tests indicate that the difference in reaction of the WIG20 (and other WSE indices under study) to bad or good news is insignificant. This contradicts the underreaction and overreaction hypothesis.

Open Access This article is distributed under the terms of the Creative Commons Attribution License which permits any use, distribution, and reproduction in any medium, provided the original author(s) and the source are credited. 


\section{References}

Andersen T, Bollerslev T, Diebold F, Vega C (2007) Real-time price discovery in global stock, bond and foreign exchange markets. J Int Econ 73:251-277

Andritzky JR, Bannister GJ, Tamirisa NT (2007) The impact of macroeconomic announcements on emerging market bonds. Emerg Markets Rev 8:20-37

Balduzzi P, Elton E, Green C (2001) Economic news and bond prices: evidence from the US treasury market. J Financ Quant Anal 36:523-542

Bollerslev T, Cai J, Song FM (2000) Intraday periodicity, long memory volatility, and macro-economic announcement effects in the US treasury bond market. J Empir Financ 7:37-55

Bonfim AN (2003) Pre-announcement effects, news effects, and volatility: monetary policy and the stock market. J Bank Financ 27:133-151

Boyd JH, Hu J, Jagannathan R (2005) The stock market's reaction to unemployment news: why bad news is usually good for stocks. J Financ 60:649-672

Brennan MJ, Jegadeesh N, Swaminathan B (1993) Investment analysis and the adjustment of stock-prices to common information. Rev Financ Stud 6:799-824

Chen NF, Roll R, Ross S (1986) Economic forces and the stock market. J Bus 59:383-403

Corrado CJ (2011) Event studies: a methodology review. Acc Financ 51:207-234

Corrado CJ, Truong C (2008) Conducting event studies with Asia-Pacific security market data. Pac-Basin Financ J 16:493-521

Corrado CJ, Zivney TL (1992) The specification and power of the sign test in event study hypothesis tests using daily stock returns. J Financ Quant Anal 27:465-478

Dimpfl T (2011) The impact of US news to the German stock market—an event study analysis. Q Rev Econ Financ 51:389-398

Entorf H, Steiner C (2007) Makroökonomische Nachrichten und die Reaktion des 15-Sekunden-DAX: Eine Ereignisstudie zur Wirkung der ZEW Konjunkturprognose. Jahrb. Nationalökonomie Stat 227:2-26

Flannery MJ, Protopapadakis A (2002) Macroeconomic factors do influence aggregate stock returns. Rev Financ Stud 15:751-782

Fleming MJ, Remolona EM (1997) What moves the bond market. Econ Policy Rev 3:31-50

Furfine C (2001) Do macro announcements still drive the US bond market? BIS Q Rev 49-57

Geske R, Roll R (1983) The fiscal and monetary linkage between stock returns and inflation. J Financ 38:1-33

Green CT (2004) Economic news and the impact of trading on bond prices. J Financ 59:1201-1233

Gurgul H, Suliga M, Wójtowicz T (2012) Responses of the Warsaw stock exchange to the US macroeconomic data announcements. Manag Econ 12:41-60

Harju K, Hussain SM (2011) Intraday seasonalities and macroeconomic news announcements. Eur Financ Manag 17:367-390

Jones B, Lin C-T, Masih AMM (2005) Macroeconomic announcements, volatility, and interrelationships: an examination of the UK interest rate and equity markets. Int Rev Financ Anal 14:356-375

Kothari SP, Shu S, Wysocki P (2009) Do managers withhold bad news? J Acc Res 47:241-276

Krueger AB (1996) Do markets respond more to more reliable labor market data? Unpublished paper, Princeton University, A test of market rationality

Li L, Engle RF (1998) Macroeconomic announcements and volatility of treasury futures. Discussion paper 98-27, Department of Economics, University of California San Diego

Li L, Hu ZF (1998) Responses of stock markets to macroeconomic announcements across economic states. IMF Working Paper 1998, No. 79

McQueen G, Roley VV (1993) Stock prices, news and business conditions. Rev Financ Stud 6:683-707

Nikkinen J, Sahlström P (2004) Scheduled domestic and US macroeconomic news and stock valuation in Europe. J Multinatl Financ Manag 14:201-245

Nikkinen J, Omran M, Sahlström P, Äijö J (2006) Global stock market reactions to scheduled US macroeconomic news announcements. Glob Financ J 17:92-104

Pearce DK, Roley V (1985) Stock prices and economic news. J Bus 58:49-67

Schwert GW (1981) Measuring the effects of regulation: evidence from the capital markets. J Law Econ 24:121-145 